\title{
Stopped-Flow/Rapid-Quenching Study of the Reaction of 1,1-Diphenylethylene and $\mathrm{CF}_{3} \mathrm{SO}_{3} \mathrm{H}^{*}$
}

\author{
Kunihide TAKARABE and Toyoki KUnITAKE** \\ Department of Organic Synthesis, Faculty of Engineering, Kyushu University, \\ Hakozaki, Higashi-ku, Fukuoka 812, Japan.
}

(Received September 29, 1979)

\begin{abstract}
The reaction of 1,1-diphenylethylene (DPE) and $\mathrm{CF}_{3} \mathrm{SO}_{3} \mathrm{H}$ was studied in dichloroethane at $30^{\circ} \mathrm{C}$ by stopped-flow/rapid-scan spectroscopy. The formation of the monomer cation was a fairly clean second-order process with the rate constant of $3400 \mathrm{M}^{-1} \mathrm{~s}^{-1}$. The absence of the dimer cation in the early stage of the reaction was confirmed by rapid quenching $\left(\mathrm{CH}_{3} \mathrm{ONa}\right.$ in $\mathrm{CH}_{3} \mathrm{OH}$ ) of the reaction mixture. The monomer cation was slowly converted into a cyclic dimer product (indanic dimer) in a few hours. Linear dimers could not be detected even after prolonged reaction. These results are in sharp contrast with those of Evans and coworkers who observed the exclusive formation of the linear dimer (in benzene with a variety of acidic catalysts). The "autosolvated" dimer cation proposed by Sigwalt and coworkers could not be observed in our experiments.

KEY WORDS Diphenylethylene / Trifluoromethanesulfonic Acid / Stopped-Flow Technique / Rapid-Scan Spectroscopy / Cationic Polymerization /
\end{abstract}

The acid-catalyzed dimerization of 1,1-diphenylethylene has been studied as a model reaction for the cationic polymerization of vinyl monomers. Almost 30 years ago, Evans, ${ }^{1}$ and Gold and Tye $^{2}$ observed a new absorption peak in the visible spectrum when diphenylethylene was dissolved in concentrated sulfuric acid, and they ascribed this peak to the diphenylethyl cation. Subsequently, Evans and his coworkers carried out extensive investigation on the dimerization process of diphenylethylene using a variety of cationic initiators. ${ }^{3-8}$

More recently, Szwarc and coworkers studied the reaction of diphenylethylene with strong electron acceptors such as $\mathrm{SbCl}_{5}{ }^{9}$ and tetranitromethane. ${ }^{10}$ Sigwalt and coworkers ${ }^{1-13}$ examined the reaction of diphenylethylene with metal halides $\left(\mathrm{TiCl}_{4}\right.$ and $\mathrm{AlCl}_{3}$ ) and $\mathrm{CF}_{3} \mathrm{SO}_{3} \mathrm{H}$ at low temperatures and discussed the initiation mechanism in detail. A similar study with $\mathrm{BF}_{3}$ was reported by Bywater and Worsfold. ${ }^{14}$

* Contribution No. 550 from Department of Organic Synthesis.

** Correspondence should be addressed to this author.
The stopped-flow/rapid-scan spectrophotometry coupled with the rapid-quenching technique has distinct advantages over previous techniques for following the fast reaction of short-lived intermediates. We have already applied this technique to the cationic polymerization of styrene and its derivatives with the $\mathrm{CF}_{3} \mathrm{SO}_{3} \mathrm{H}$ initiator and determined the rate constants of the elementary steps. ${ }^{15-18}$ Similar studies were published on substituted styrenes by Sawamoto and Higashimura. ${ }^{19,20}$

In this paper, we report on the dimerization process of 1,1-diphenylethylene by $\mathrm{CF}_{3} \mathrm{SO}_{3} \mathrm{H}$ as studied by the stopped-flow/rapid-quenching technique.

\section{EXPERIMENTAL}

\section{Materials}

Commercial 1,1-diphenylethylene (Tokyo Kasei Kogyo Co., purity $>99 \%$ ) was fractionally distilled, bp $107-108^{\circ} \mathrm{C} \quad(3 \mathrm{mmHg}) \quad\left[\right.$ lit. $^{21}$ bp $119.6^{\circ} \mathrm{C}$ $(5 \mathrm{mmHg})]$ and the purity was confirmed by gas chromatography and UV spectroscopy. Dichloroethane was washed with dilute aqueous 
sodium hydroxide and water, dried over $\mathrm{CaCl}_{2}$, distilled from $\mathrm{P}_{2} \mathrm{O}_{5}$, and stored over Molecular Sieve

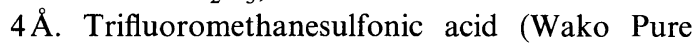
Chemical Co., special grade) was used without further purification. Quenching solutions were prepared by dissolving calculated amounts of sodium metal in methanol.

\section{Procedures}

The reaction was followed by a stoppedflow/rapid-scan spectrophotometer (Union Giken Co., Model RA 1300), in the same procedure as described before. ${ }^{16}$ The quenching procedure has been also explained. ${ }^{16}$

\section{RESULTS AND DISCUSSION}

Reaction of 1,1-Diphenylethylene with Excess $\mathrm{CF}_{3} \mathrm{SO}_{3} \mathrm{H}$

The spectral change in the reaction of diphenylethylene (DPE) and $\mathrm{CF}_{3} \mathrm{SO}_{3} \mathrm{H}$ was first studied in the presence of excess $\mathrm{CF}_{3} \mathrm{SO}_{3} \mathrm{H}$. An absorption peak appeared at $435 \mathrm{~nm}$ immediately on mixing the two reagents. Olah et al. ${ }^{22}$ reported that the methyldiphenylcarbonium ion I possessed the absorption maximum at $422 \mathrm{~nm}$ in $\mathrm{FSO}_{3} \mathrm{H}-\mathrm{SbF}_{5}$ at $-60^{\circ} \mathrm{C}$. Fleischfresser et al. ${ }^{9}$ produced the same cation $\left(\lambda_{\max }=435 \mathrm{~nm}\right)$ from 1,1-diphenylethanol and $\mathrm{SbCl}_{5}\left(\mathrm{CH}_{2} \mathrm{Cl}_{2},-80^{\circ} \mathrm{C}\right)$. The 435 -nm species may thus be assigned as I, which is produced by the simple protonation of diphenylethylene. The absorbance becomes maximal in $100-150 \mathrm{~ms}$ and then decreases gradually within a period of $2-3$ seconds. Another absorption peak appeared at $c a .600 \mathrm{~nm}$ only $1-2$ seconds after the mixing, and the peak height leveled off in $10 \mathrm{~s}$. The reaction appears to be quite clean during the initial one second. Figure 1 shows the time course of these spectral changes.
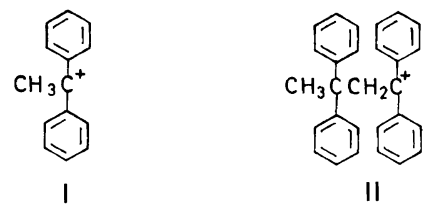

This spectral result is in contrast with those observed by Sauvet et al. ${ }^{11}$ These authors noted the formation of (at least) three cationic species in the UV spectra, although NMR spectra indicated that monomeric cation $\mathbf{I}$ was the major species. According to them, a main peak at $435 \mathrm{~nm}$ is attributable to both the monomeric (I) and dimeric (II) cations, whereas a $520 \mathrm{~nm}$ absorption can be assigned to the monomer-solvated form of I and II. Their third absorption at $456 \mathrm{~nm}$ was considered to be due to a dimeric cation stabilized through the $\beta$ phenyl ring interaction.

The UV spectral observation is made simple in the present study probably because the reaction time is very short and the monomer concentration is low. However, we cannot decide from the spectral data alone whether the species absorbing at $435 \mathrm{~nm}$ is monomeric (I) or dimeric (II) cation, or both. This question can be resolved by the rapid-quenching experiment.

Equal amounts ( $20 \mathrm{ml}$ each) of the dichloroethane solutions of monomer $\left(1.73 \times 10^{-3} \mathrm{M}\right)$ and

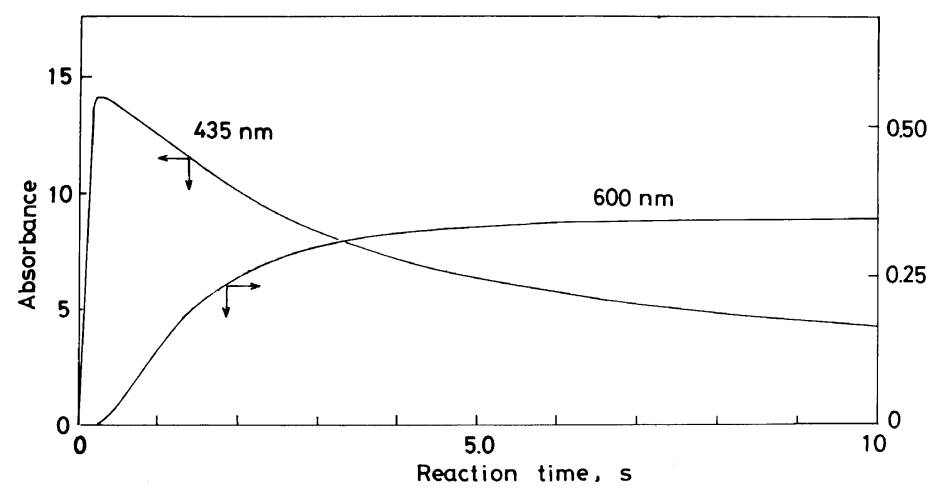

Figure 1. Time course of the absorbance change: temp, $30^{\circ} \mathrm{C}$; solvent, dichloroethane; DPE, $0.45 \mathrm{mM}$; $\mathrm{CF}_{3} \mathrm{SO}_{3} \mathrm{H}, 19 \mathrm{mM}$. 
$\mathrm{CF}_{3} \mathrm{SO}_{3} \mathrm{H}\left(3.48 \times 10^{-2} \mathrm{M}\right)$ were mixed at $30^{\circ} \mathrm{C}$ in the rapid-quenching apparatus and $20 \mathrm{ml}$ of a quenching solution $\left(8.70 \times 10^{-2} \mathrm{M} \mathrm{CH} \mathrm{CH}_{3} \mathrm{ONa}\right.$ in $\left.\mathrm{CH}_{3} \mathrm{OH}\right)$ was introduced $100 \mathrm{~ms}$ later. This procedure was repeated 15 times and the combined reaction mixtures were washed with water, dried over $\mathrm{CaCl}_{2}$ and the solvent removed. The oily residue was subjected to high-pressure liquid chromatography: column, Hitachi gel $3019,8 \phi \times 500$; solvent, methanol-

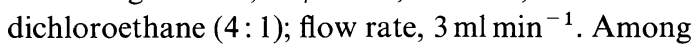
the three major peaks observed, the first, broad peak at $6--10 \mathrm{~min}$, was attributed to the unidentified reaction product of $\mathrm{CF}_{3} \mathrm{SO}_{3} \mathrm{H}$ and dichloroethane (and the quenching solution), since the same peak was found in the absence of monomer. The third peak at $15 \mathrm{~min}$ was identified to be the unreacted monomer. The fractions corresponding to the second peak (12.5 $\mathrm{min}$ ) was collected to give colorless needles, mp $32-33^{\circ} \mathrm{C}$, after solvent removal. This compound was shown to be 1-methoxy-1,1diphenylethane III by NMR spectroscopy; NMR $\left(\mathrm{CDCl}_{3}\right) \delta 1.75\left(\mathrm{~s}, 3, \mathrm{CH}_{3}\right), 3.05\left(\mathrm{~s}, 3, \mathrm{CH}_{3} \mathrm{O}\right)$ and 7.2 ppm (m, 10, aromatic).<smiles>COC(C)(c1ccccc1)c1ccccc1</smiles>

III

These results clearly show that simple protonation is the only detectable reaction occurring at the early stage $(<1 \mathrm{~s})$ in the presence of excess $\mathrm{CF}_{3} \mathrm{SO}_{3} \mathrm{H}$.

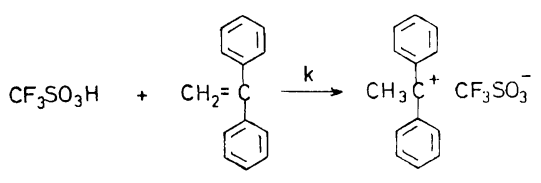

The relative amounts of monomer and the quenched product III in the quenched mixture were readily determined by NMR or UV spectroscopy. In the NMR spectrum, the relative peak area of the singlet methylene proton of DPE and the methoxy proton of III was used. Table I gives some examples of this reaction. Undoubtedly, the reaction is very fast, and appears to have reached equilibria of the monomer and monomer cation in $100 \mathrm{~ms}$, as the monomer consumption is always $c a .80 \%$. The extent of the reaction was compared with the absorbance at $435 \mathrm{~nm}$ of the reaction mixture under the same conditions and the molar extinction coefficient of the cation was estimated to be $31,000 \pm 2,000 \mathrm{M}^{-1}$ $\mathrm{cm}^{-1}$. This value is close to that given by Fleischfresser et al. $\left(33,000 \mathrm{M}^{-1} \mathrm{~cm}^{-1}\right),{ }^{9}$ but is smaller than the one reported by Bertoli and Plesch $\left(39,000 \mathrm{M}^{-1} \mathrm{~cm}^{-1}\right),{ }^{23}$ by Sauvet et al. $\left(36,000 \mathrm{M}^{-1}\right.$ $\left.\mathrm{cm}^{-1}\right)^{12}$ and by Olah et al. $\left(37,000 \mathrm{M}^{-1} \mathrm{~cm}^{-1}\right) .{ }^{22}$

Subsequently the kinetics of protonation were studied by stopped-flow spectroscopy. The initial rate of the carbocation formation was first-order with respect to monomer and $\mathrm{CF}_{3} \mathrm{SO}_{3} \mathrm{H}$ as shown in Figures 2 and 3, respectively.

$$
v_{\mathrm{i}}=\left(\frac{\mathrm{d}\left[\mathrm{P}^{+}\right]}{\mathrm{d} t}\right)_{t=0}=k[\mathrm{DPE}]\left[\mathrm{CF}_{3} \mathrm{SO}_{3} \mathrm{H}\right]
$$

A second-order rate constant of $3,400 \pm 400 \mathrm{M}^{-1}$ $\mathrm{s}^{-1}$ was obtained. The apparent rate constants were insensitive to the water concentration when it was kept below ca. $3 \mathrm{mM}$.

The lifetime of the monomeric cation is $1-2 \mathrm{~min}$ under the conditions of this study. Concurrent with the decrease in the 435-nm absorption, a new absorption appeared at $600 \mathrm{~nm}$ as shown in Figure 1. The intensity of this peak becomes maximal in $10 \mathrm{~s}$, and remains constant. This reaction mixture contains a third component as shown by a liquid chromatogram: retention time, ca. 17 min under standard conditions. This component was shown to be an indanic dimer IV as is discussed below. Table II shows the variation in the product distribution of the quenched reaction mixture. In the early stage of the reaction, only the monomeric cation $\mathbf{I}$ is formed, since III is the only product of quenching. However, the content of III is decreased very much and a considerable amount of IV is formed instead, when the reaction mixture is allowed to stand for $23 \mathrm{~h}$. This suggests that the indanic dimer is slowly formed from the monomeric cation I. The absorption peak at $600 \mathrm{~nm}$ seems to be related to the dimer formation.

Reaction of $\mathrm{CF}_{3} \mathrm{SO}_{3} \mathrm{H}$ with Excess Diphenylethylene In the presence of excess DPE ( $c a .1 \mathrm{M})$, the reaction could not be followed by UV spectroscopy due to the large absorbance of the monomeric cation. Therefore, the product characterization was performed by liquid chromatography.

A $10 \mathrm{ml}$ solution of diphenylethylene in dry dichloroethane $(0.54 \mathrm{M})$ and $10 \mathrm{ml}$ of $0.014 \mathrm{M} \mathrm{CF}_{3} \mathrm{SO}_{3} \mathrm{H}$ in the same solvent were rapidly mixed at room temperature $\left(16^{\circ} \mathrm{C}\right)$. The reaction mixture turned from orange to green and then to dark green. It was 
Table I. Protonation reaction of diphenylethylene $\mathrm{e}^{\mathrm{a}}$

\begin{tabular}{|c|c|c|c|c|}
\hline DPE & $\mathrm{CF}_{3} \mathrm{SO}_{3} \mathrm{H}$ & Methoxylated product, $\mathbf{I I I}^{\mathbf{b}}$ & Monomer consumption ${ }^{b}$ & of otion $125 \mathrm{~nm}$ \\
\hline $\mathrm{mM}$ & $\mathrm{mM}$ & $\mathrm{mM}$ & $\%$ & $\max$ \\
\hline 0.072 & 23 & 0.056 & 78 & 30,000 \\
\hline 0.091 & 19 & 0.072 & 79 & 33,000 \\
\hline 0.214 & 23 & 0.176 & 82 & 29,000 \\
\hline
\end{tabular}

a Condition: reaction temp, $30^{\circ} \mathrm{C}$, solvent, dichloroethane; reaction time, $100 \mathrm{~ms}$.

b Determined from liquid chromatograms of the quenched product.

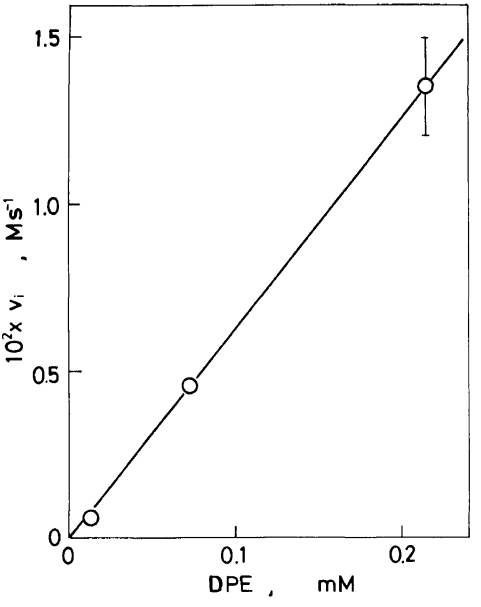

Figure 2. Dependence of the initial rate of protonation on the DPE concentration: temp, $30^{\circ} \mathrm{C}$; solvent, dichloroethane; $\mathrm{CF}_{3} \mathrm{SO}_{3} \mathrm{H}, 23 \mathrm{mM}$.

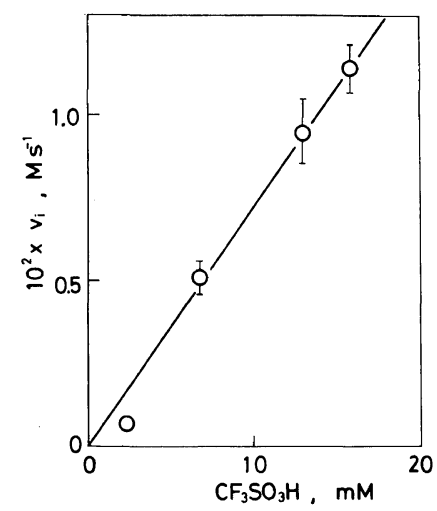

Figure 3. Dependence of the initial rate of protonation on the $\mathrm{CF}_{3} \mathrm{SO}_{3} \mathrm{H}$ concentration: temp, $30^{\circ} \mathrm{C}$; dichloroethane; DPE, $0.143 \mathrm{mM}$. quenched with $\mathrm{CH}_{3} \mathrm{ONa}$ in $\mathrm{CH}_{3} \mathrm{OH} 24 \mathrm{~h}$ later and the mixture was washed and dried over $\mathrm{CaCl}_{2}$. Three components were detected in a liquid chromatogram of the product. The first and second components were identified to be III and DPE by comparison with standard samples. The third component was separated by liquid chromatography and recrystallized from dichloroethane, $\mathrm{mp} 145-147^{\circ} \mathrm{C}$ (lit. ${ }^{23}$ $143^{\circ} \mathrm{C}$ ). NMR, IR spectra, and elemental analysis results were consistent with the so-called indanic dimer IV. ${ }^{24}$

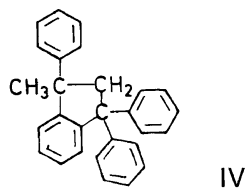

The product distribution was subsequently determined under several conditions by liquid chromatography, and the results are summarized in Table III. It is seen that the indanic dimer becomes the predominant product after sufficient reaction time. Other products such as linear dimers were not formed.

The Course of Reaction of Diphenylethylene with $\mathrm{CF}_{3} \mathrm{SO}_{3} \mathrm{H}$

The predominant course of reaction of diphenylethylene with $\mathrm{CF}_{3} \mathrm{SO}_{3} \mathrm{H}$ can be summarized as in Scheme I on the basis of the present study.

The initial protonation process is very fast and the second-order rate constant determined from the initial rate is $3400 \mathrm{M}^{-1} \mathrm{~s}^{-1}$ at $30^{\circ} \mathrm{C}$ in dichloroethane. However, this reaction is not completed even if an excess of $\mathrm{CF}_{3} \mathrm{SO}_{3} \mathrm{H}$ is present. As shown in Table II, $80 \%$ of diphenylethylene was protonated in one second, but $10 \%$ of the diphenylethylene remained after $23 \mathrm{~h}$ under almost the same conditions. 
Reaction of Diphenylethylene and $\mathrm{CF}_{3} \mathrm{SO}_{3} \mathrm{H}$

Table II. Product distribution ${ }^{\mathbf{a}}$

\begin{tabular}{|c|c|c|c|c|}
\hline DPE & $\mathrm{CF}_{3} \mathrm{SO}_{3} \mathrm{H}$ & Reaction temp & Pention timo & Product \\
\hline $\mathrm{mM}$ & $\mathrm{mM}$ & ${ }^{\circ} \mathrm{C}$ & & \\
\hline 0.45 & 19 & 30 & $1 \mathrm{~s}$ & $20 \%$ DPE, $80 \%$ III \\
\hline 0.45 & 25 & 26 & $23 \mathrm{~h}$ & $10 \%$ DPE, $42 \%$ III, $48 \%$ IV \\
\hline
\end{tabular}

a Reaction conditions: temp, $30^{\circ} \mathrm{C}$, solvent, dichloroethane, [DPE] $\ll\left[\mathrm{CF}_{3} \mathrm{SO}_{3} \mathrm{H}\right]$.

Table III. Product distribution ${ }^{\mathrm{a}}$

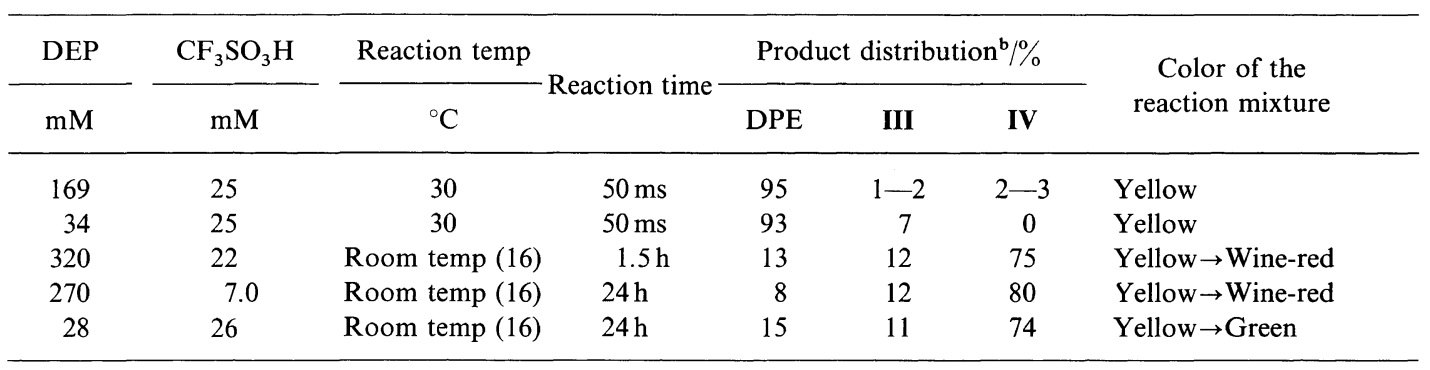

a Reaction conditions: solvent, dichloroethane; $[\mathrm{DPE}]>\left[\mathrm{CF}_{3} \mathrm{SO}_{3} \mathrm{H}\right]$.

b Determined by liquid chromatography.

\section{Scheme I}

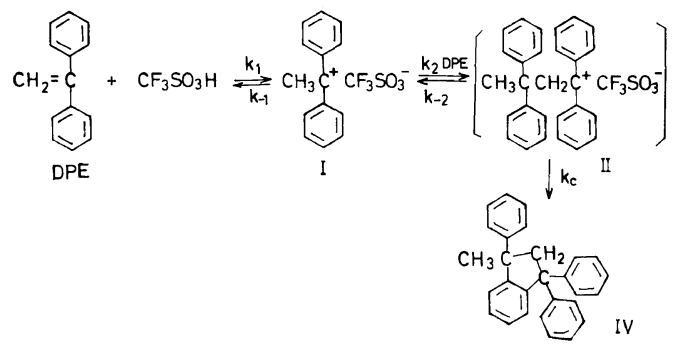

Apparently, the monomer and the monomeric cation become equilibrated in $0.1-1 \mathrm{~s}$ (see Figure 1). Thus, the apparent rate constant of protonation $k_{\text {app }}$ is actually given by

$$
k_{\text {app }}=k_{1}\left[\mathrm{CF}_{3} \mathrm{SO}_{3} \mathrm{H}\right][\mathrm{DPE}]-k_{-1}[\mathrm{I}]
$$

and the above-mentioned second-order rate constant of protonation is the lower limit of the rate constant of the forward reaction in the protonation process. The $k_{2}$ process can be neglected during the early stage of the reaction. The monomer cation may exist in the form of a free ion or an ion pair. However, these species, if present, cannot be differentiated spectroscopically, since it has been shown that the polystyryl cation gives a single $\lambda_{\max }$ value $(340 \mathrm{~nm})$ without regard to whether or not it is a free-ion or a paired ion. ${ }^{17,18}$

We could not detect the methoxy-terminated product of the linear dimer cation II in the quenching experiment. The indanic dimer must be formed by the intramolecular electrophilic attack of dimer cation II. It seems that the equilibrium between the monomer cation and the dimer cation is overwhelmingly in favor of the former, and the dimer cation formed should rapidly revert to the monomer cation or cyclize to the indanic dimer.

The slowly-appearing absorption at $600 \mathrm{~nm}$ cannot be attributed to the dimer cation or to an intermediate leading to the indanic dimer.

Sauvet et al. reported the observation of a supplementary absorption at $456 \mathrm{~nm}$ in the presence of excess diphenylethylene relative to $\mathrm{CF}_{3} \mathrm{SO}_{3} \mathrm{H}$, and assigned it to the "autosolvated" dimeric cation $\mathbf{V}$.

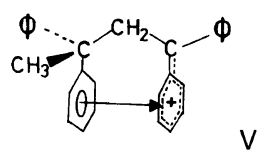


However, this is not likely since the quenching product of linear dimers could not be found in our experiment. Bywater and Worsfold ${ }^{14}$ reported the formation of the triphenylmethyl cation from the indanic dimer in the system of DPE- $\mathrm{BF}_{3} \cdot \mathrm{H}_{2} \mathrm{O}$ $\mathrm{CH}_{2} \mathrm{Cl}_{2}$. We suspect that the 600 -nm-absorbing species is a highly delocalized carbocation structurally related to the indanic dimer. The methoxide quenching may convert this species to the indanic dimer.

In earlier days, Evans and his coworkers made extensive kinetic investigations on the linear dimerization of diphenylethylene.

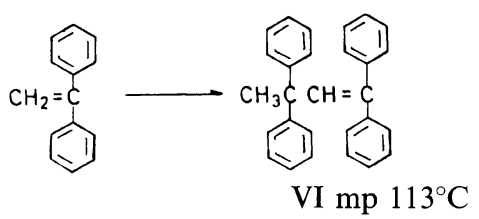

The catalysts used by these authors include trichloroacetic acid, ${ }^{3}$ iodine, ${ }^{4} \mathrm{SnCl}_{4}-\mathrm{H}_{2} \mathrm{O},{ }^{5} \mathrm{SnCl}_{4}-$ $\mathrm{HCl},{ }^{7} \mathrm{TiCl}_{4}-\mathrm{HCl}^{8}$ and $\mathrm{Sb}_{2} \mathrm{Cl}_{6}-\mathrm{HCl}^{25}$ and the solvent in most cases was benzene. The reaction slowly proceeded to completion, for $10-100 \mathrm{~h}$ at $30-40^{\circ} \mathrm{C}$. The linear dimer was very slowly (in $100-1000 \mathrm{~h}$ ) converted to the indanic dimer by $\mathrm{SnCl}_{4}{ }^{26}$ or by $\mathrm{Sb}_{2} \mathrm{Cl}_{6}-\mathrm{HCl}^{25}$ These results are quite different from our data and those of the Sigwalt group, in that the indanic (cyclized) dimer is the only dimeric product. In fact, the equilibrium between the monomeric and dimeric cation was shown to shift far to the monomeric side in both this study and that by Sauvet $e t$ $a l .{ }^{11}$ Evans and his coworkers followed the very slow reaction of diphenylethylene by dilatometry in the presence of rather large amounts of catalyst. Therefore, they must have been pursuing the secondary reaction characterized by volume decrease. These slow processes cannot be directly related to our spectroscopic/quenching data.

Recently, Higashimura and Nishi reported the simultaneous formation of the linear and cyclic dimers in the acid-catalyzed dimerization of $\alpha$ methylstyrene. ${ }^{27}$ The formation of the cyclic dimer increased with increasing polarity of the solvent. These results suggest that the discrepancy between our results and those of Evans also come from the difference in solvent: dichloroethane $v s$. benzene.
The influence of the solvent and initiator on the dimerization process of diphenylethylene will be treated in a future publication.

\section{REFERENCES}

1. A. G. Evans, J. Appl. Chem., 1, 240 (1951).

2. V. Gold and F. L. Tye, J. Chem. Soc., 2172 (1952).

3. A. G. Evans, N. Jones and J. H. Thomas, J. Chem. Soc., 1824 (1955).

4. A. G. Evans, P. M. S. Jones and J. H. Thomas, $J$. Chem. Soc., 2095 (1957).

5. A. G. Evans and J. Lewis, J. Chem. Soc., 2975 (1957).

6. A. G. Evans, P. M. S. Jones and J. H. Thomas, $J$. Chem. Soc., 4563 (1958).

7. A. G. Evans and J. Lewis, J. Chem. Soc., 1946 (1959).

8. A. G. Evans and E. D. Owen, J. Chem. Soc., 4123 (1959).

9. B. E. Fleischfresser, W. J. Cheng, J. M. Pearson and M. Szwarc, J. Am. Chem. Soc., 90, 2172 (1968).

10. S. Penczek, J. Jagur-Grodzinski, and M. Szwarc, $J$. Am. Chem. Soc., 90, 2174 (1968).

11. G. Sauvet, J. P. Vairon, and P. Sigwalt, J. Polym. Sci., Polym. Symp., No. 52, 173 (1975).

12. G. Sauvet, J. P. Varion, and P. Sigwalt, J. Polym. Sci., Polym. Chem. Ed., 16, 3047 (1978).

13. M. Masure, G. Sauvet, and P. Sigwalt, J. Polym. Sci., Polym. Chem. Ed., 16, 3065 (1978).

14. S. Bywater and D. J. Worsfold, Can. J. Chem., 55, 85 (1977).

15. T. Kunitake and K. Takarabe, J. Polym. Sci., Polym. Symp., No. 56, 33 (1976).

16. T. Kunitake and K. Takarabe, Polym. J., 10, 105 (1978).

17. K. Takarabe and T. Kunitake, Macromolecules, 12 , 1061 (1979).

18. K. Takarabe and T. Kunitake, Macromolecules, 12, 1067 (1979).

19. M. Sawamoto and T. Higashimura, Macromolecules, 11, 328 (1978).

20. M. Sawamoto and T. Higashimura, Macromolecules, 11, 501 (1978).

21. C. F. H. Allen, S. Converse, Org. Synth., I, 226 (1941).

22. G. A. Olah, C. U. Pittman, R. Waack, and M. Doran, J. Am. Chem. Soc., 88, 1488 (1966).

23. V. Bertoli and P. H. Plesch, Spectrochim. Acta, 25-A, 447 (1969).

24. C. S. Schoepple and J. D. Ryan, J. Am. Chem. Soc., 52, 4021 (1930).

25. A. G. Evans and D. Price, J. Chem. Soc., 2982 (1959).

26. A. G. Evans, E. A. James and E. D. Owen, J. Chem. Soc., 3532 (1961).

27. T. Higashimura and H. Nishi, J. Polym. Sci., Polym. Chem. Ed., 15, 9 (1977). 